\title{
Not Known if BRAF Mutation Analysis Was Performed
}

National Cancer Institute

\section{Source}

National Cancer Institute. Not Known if BRAFMutation Analysis Was Performed. NCI

Thesaurus. Code C160433.

An indication that it is not known whether BRAF mutation analysis was performed during the study. 